\title{
Development of Mineral Processing Engineering Education in WUST
}

\author{
Gongming Qian ${ }^{a^{*}}$, Fu Yang, Tiejun Chen and Tao Liu \\ School of Resource and Environmental Engineering, \\ Wuhan University of Science and Technology, Wuhan, China \\ amoneyfamous@163.com, ${ }^{\text {b}} 542734663 @ q q . c o m,{ }^{c}$ chentiejun@wust.edu, ${ }^{d}$ liutao@wust.edu \\ ${ }^{*}$ The Corresponding author
}

Keywords: Engineering education; Mineral processing; Personal training; Teaching reform

\begin{abstract}
Mineral processing which plays a key role in steel industry, is giving more and more attention and mineral processing engineering education has been given high priority in China. Lack of mineral resource and pollution has baffled the economy development of China. Taking the personnel training of metallurgy mineral resources processing and utilization as a background, the development of mineral processing engineering education in Wuhan University of Science and Technology (WUST) is introduced in this paper. The faculty group, laboratory and scientific research conditions of the discipline are presented. The personnel training scheme of the subject, the courses system, student criterion are also discussed, and how to cultivate excellent graduates in mineral processing engineering field to meet the demand of high education internationalization are discussed.
\end{abstract}

\section{Introduction}

Iron and steel is the most important supporting materials in industry, which accounts for $95 \%$ in products of machinery manufacturing. As the main resources, iron ore decided the mineral processing techniques are dominant, and have a very wide field of application in the metals industries[1]. More than 3000 years ago, the ancient Chinese had mastered and practiced distinguishing and sorting diverse minerals and hence developed technology for the alloy's composition of bronze casting[2]. In present, the characteristics of China's metallurgy mineral resources, such as low-grade fine-grained complicated composition, difficulties in mining and separation, a low level of utilization and environmental pollution has baffled the iron industry development of China[3]. Although some new technologies such as direct reduction can be used extracting metal to replace mineral processing, but mineral processing methods are inexpensive, and their use is readily justified on economic grounds[4]. Thus research on mineral processing is giving more and more attention and mineral processing engineering education has been given high priority in China[5]. Now, about 40 universities set up the major of mineral processing engineering. Accordingly, lots of technical personnel in the field of mineral processing engineering graduated from many universities and research institutes, which meet the demand of economic development in China.

WUST is a key public higher learning institution claiming traditional strengths in engineering and sciences, and it is one of university strength and characterize in the discipline of mineral processing engineering. It is a high-level university operated under the joint aegis of Hubei Provincial Government, Ministry of Education of PRC and 6 largest mega steel enterprises in China. It is also one of universities chosen into the program of National Basic Ability Construction Project of Western and Central China. With the development of over 110 years, WUST has formed a discipline major system with a priority to engineering and science, and combined with contemporary popular disciplines such as medicine, economics, management, humanities, art, law, and philosophy. WUST currently has 2674 staffs, which includes 1841 faculties, 8 academicians of the Chinese Academy of Engineering, 1 scholar accredited with the "Cheung Kong Scholars Programme" sponsored by the Central Government, 6 scholars accredited with the national "1000 Talents Plan", 9 scholars accredited with the Hubei provincial "100 Top Talents Project for 
Innovation" and 60 distinguished professors accredited with the Chutian Project, over 1000 are professors, associate professors and senior researchers. There are more than 32000 students in WUST.

\section{Development of Mineral Processing Engineering Education in WUST}

The beginning of China's mineral processing engineering education is the discipline of mineral processing engineering was founded in the Beijing College of Mining and Technology in 1952[6]. The institution began offering undergraduate degrees of mineral processing engineering in 1973 upon the establishment of Wuhan Iron and Steel Institute, the University's forerunner in the modern times. Thereafter the discipline was going to develop and grow in strength on a never straight road. It was authorized by the State to confer master's degree in 1983, doctoral degree in 2011 and postdoctoral scientific research station in 2014. It entered into the key disciplines of Hubei province, and was qualified the outstanding brand discipline of Hubei province in 2007, as well as was selected as the national characteristic specialty in 2010, Hubei comprehensive reform pilot in 2013 and the specialty of "the Plan for Educating and Training outstanding Engineers" in 2013. Nowadays, the discipline of mineral processing engineering makes great contributions to national mining industry and metallurgy industry with the predominance of fine particle mineral separation, mineral wet metallurgy, agglomeration of iron ores, mineral material, comprehensive utilization of resources, and pollution control, etc[7].

Teaching Staff. Teachers play central roles in cultivating innovative students for profession. There are 23 teaching faculties in the discipline of mineral processing engineering of WUST in present, which form a high-level scientific and researching faculty. The education background, age structure and academic title of the specialized faculty are given respectively in figure 1, figure 2 and figure 3.

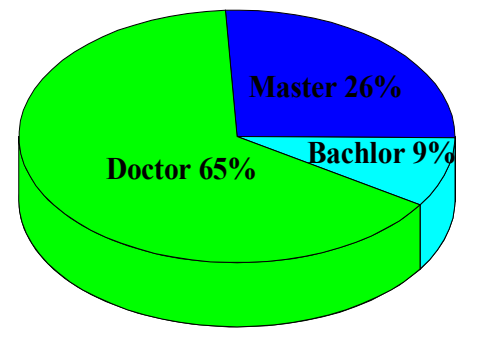

Figure 1. Education background

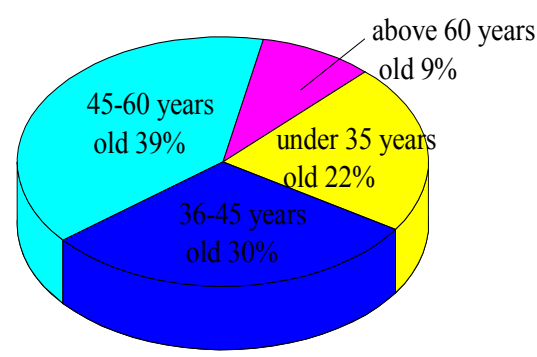

Figure 2. Age structure

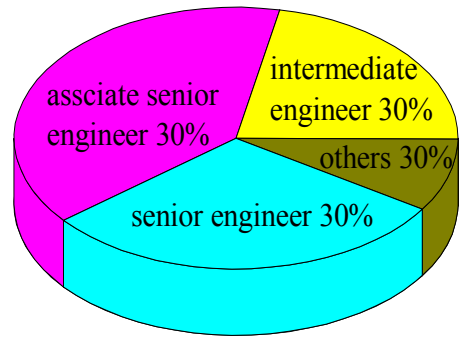

Figure 3. Academic title

The specialized faculty of the discipline obtained many kinds of honours, such as 'National Science and Technology Plan to Perform Outstanding Contribution Award' owner, 'Special Allowance Expert of the State Council' owner, 'National Outstanding Scientific and Technical Workers' owner, 'China Iron and Steel industry Outstanding Scientific and Technical Workers' owner, 'Hubei Province High Level Talents Project Selected in the New Century' owner, 'Hubei Province Outstanding Contribution Young Experts' owner, 'Hubei Province Outstanding Professional and Technical Personnel' owner, 'Hubei Youth Science and Technology Award' owner, 'Excellent teachers in Hubei Province' owner, etc. Over twenty times awards had been gained in various honor titles over provincial or national level. Taking the processing and utilization of metallurgy mineral resource and clean mineral processing technology as the feature, the discipline of mineral processing engineering was approved as a key discipline of Hubei province and a key construction unit of 'Collaborative Innovation Center' of WUST. Recently, it gets the Hubei provincial "Collaborative Innovation Center of Efficient Utilization of Vanadium Resources" for the discipline development and evolution. It has made a great contribution to the education and scientific research of mineral processing engineering in China and it also has got a high academic position and influence in this field of the world.

Experimental and Practical Conditions. This discipline of mineral processing has a strong back ground of engineering. Engineering training is very important for not only imparting the 
professional knowledge to the undergraduate students, but also learning the innovative methods and approaches of scientific research[8]. The top-ranking experimental and practical engineering cultivation system for the education of mineral processing engineering has been formed in WUST. To ensure the quality of teaching, teachers who teach specialist experiments and practical training must have an engineering background and more than five years of fieldwork experience. The laboratory possesses a lot of advanced instruments including scan electrical microscope, gas chromatography/ infrared spectrum apparatus, X-ray diffraction, the determinative instrument of molecular weight, etc. The laboratory of mineral processing engineering is the key lab of Hubei province.

Combined with the central courses of the discipline, there are many traditional experimental lessons setting for the undergraduates, such as "experimental technology of mineral processing", "metal working practice", "experiment technology of electrician and electron". At the same time, some of the experiments were extended to culture practice and innovation ability of students with participating the second lesson and scientific innovation training program. The innovative experiments, especially combining with the advanced scientific and research projects, are enrolling the undergraduates. A number of experimental research platforms of new technology for mineral processing were established, and then the depth and extent of experiment teaching were also extended. In recent years, many kinds of pilot experimental research systems were set up with the support of the "National Characteristic Specialty", the "Student's Platform for Innovation and Entrepreneurship Training Program" and the national "Plan for Educating and Training outstanding Engineers". The distinctive experimental researching systems were built based on researching projects, which including beneficiation and screening pilot scale system, metallurgy wet extraction, grinding technology and equipment, mineral material, comprehensive utilization of second resources, agglomeration and direct reduction, simulation and control system of classification, etc.. Most students can take part in the practice research projects and to develop technique training for achieving scientific exercitation, and many kinds of practical training were developed to cultivate the students' engineering capability[7].

The discipline of mineral processing engineering is the traditional strength one in WUST, and well cooperated with iron and steel plants, mines, and so on. The out school practical teaching systems of production/ learn/ research were established. So far, many metallurgy mine groups such as Baosteel Group Corporation, Wuhan Iron and Steel Group Corporation, MaGang Steel Corporation, Xiangtan Iron and Steel Corporation and so on, had selected as the steady practice bases [9]. In the plants, the students can combine the knowledge from books with the practical work, confirm the theoretical knowledge via work experience or communion with the engineers and enhance the synthetic ability of solving projects.

Personnel Training. To gain the capability of developing new technology, processing and production, industry design and organized management, undergraduates should attend the basic training of science research, process technology, engineering design methods, and production management and computer application in the discipline of mineral processing engineering[10]. The courses for training include public basic course, academic courses, professional basic courses, professional oriented courses and practical courses. Public basic courses, such as Moral Cultivation and Basics of Law, Cultural Basis of Computer Science, Philosophy principle, Physical Education, Mental Health, English, etc have been opened. The academic courses, professional basic courses and professional oriented courses are selected by the undergraduate students, such as Advanced Mathematics, Physics, Descriptive Geometry and Engineering Drawing, Electrotechnics, Electronic Technology, Organic Chemistry, Inorganic Chemistry and Analytical Chemistry, Physical Chemistry, Solid Materials Separation, Engineering Mechanics, Hydrodynamics, Research Techniques of Mineral Processing, Agglomeration, Design of Mineral Processing, Metallurgical Principles, Preparation and Transportation of Minerals, Mineral Micro-constitution, Comprehensive Utilization of Secondary Resources, and so on. Meanwhile, three times exercitation in different metallurgy raw material preparation and mineral processing plants are arranged for the students to 
learn practical skills in the plants. The students' specialized training is strengthened at the 7th semester and the employment selections are free while students have graduated.

Since 1973, more than 2000 undergraduate students, about 180 graduate students have given the mineral processing engineering education in WUST. Now, we have 352 undergraduate students, 61 graduate students and 8 doctoral students in this discipline.

\section{Teaching and Scientific Research Achievements}

In recent years, the faculties of mineral processing engineering have undertaken many projects, such as ' 863 ' National High Tech Projects, '973' National Significant Basic Research Projects, National Natural Scientific Funds Projects, National Key Industry Experiment Projects, National Innovation Engineering Projects, National Key Science and Technology Promotion Projects. Between year 2012 and 2015, 172 papers on mineral processing were published on open issued publications at home as well as abroad and 5 monographs or textbooks were published. More than 50 patents were obtained in this discipline, and we also attained the national and the province or the ministerial level rewards 18 items[11].

In the researching fields of fine particle mineral separation, agglomeration of iron ores, mineral wet metallurgy, mineral material, simulation and control of mineral processing, comprehensive utilization of mineral resources and environment protection, we had got the independent intellectual property rights of research results and have been applying to the industry. The total outlay of scientific research is up to 83910000 Yuan (RMB). The theory of the selective liberation and high energy density grinding of fine particle, valuable metal element high effective extraction theory, functional mineral material control synthesis theory and agglomeration of iron ores were founded. The method and equipment of fine particles separation were invented, such as over limited H/D spiral chute, GN systems high effective grinding mill, and realized the industrial application for comprehensive utilizing of metallurgy solid waste and oolitic hematite. The theory of dual cycle oxidation of vanadium was developed and the flow sheet is commercial application in 19 companies. The theory of classification was put forward and classify facility is well employed in metallurgy industry and mineral processing industry. These technologies have made great contribution to improve the efficiency of metallurgy utilization and environment protection.

At the same way, the undergraduates were involved in and did many experimental or research works under the direction of supervisors. And they can use the equipment and systems in the laboratory or in the experiment classes skillfully. In this way, the students could learn and master the necessary engineering skills to do experiments or research by themselves. For the undergraduates, 'Scientific research training program' is set up to encourage the students to take part in the research works, and experienced professors and researchers were selected as supervisors strictly.

Academic Communication. With the internationalization of higher engineering education, the discipline of mineral processing engineering has established cooperative relationship with more than 20 abroad universities and institutes of United States, German, Australia, Canada, Mexico, Japan, Russian, Poland, Chili, South Africa, etc. More than 30 undergraduate and graduate students were associated training with these universities and institutes. Over 10 international or national academic conferences have sponsored by the department of mineral processing engineering. More than 100 teachers lectured abroad and attended international academic conferences. More and more international projects were completed by the international cooperation, and a large number of engineers were needed, especially in the field of mineral processing. International engineering education for mineral processing is being our new object in cultivation of undergraduates. And now, we also have been accepted international or national scholar in advanced studies by many abroad universities. 


\section{Epilogue}

The discipline of mineral processing engineering in WUST is building into an international top-ranking discipline with the effort of the faculties. With the trend of higher engineering education internationalization, internationalization strategy for mineral processing engineering education is being our new object in cultivation of undergraduates. To make the distinctive fields, hold national researching projects and strengthen primary research, cultivate excellent undergraduates, it will attain the international top-ranking level in mineral processing engineering education.

\section{Acknowledgments}

This work is support by the project of the construction point of the national special discipline (TS12290), the project of Hubei Province Teaching Research (2010181) and the WUST Teaching Research Project (2011x036).

\section{References}

[1] B.A. Wills and J. Finch: Wills' Mineral Processing Technology: An Introduction to the Practical Aspects of Ore Treatment and Mineral Recovery (Elsevier, USA 2016).

[2] D.Z. Wang, G.Z. Qiu, Y.H. Hu and G. Yao: XXIV International Mineral Processing Congress (Beijing, China, September 24-28, 2008), p.3.

[3] R.Z. Hu, J.M. Liu and M.G. Zhai: Mineral Resources Science and Technology in China: A Roadmap to 2050 (Science Press Beijing, China, 2010).

[4] M. Komatina and H.W. Gudenau: Metalurgija, vol. 10 (2004), No.4, p.309.

[5] X.X. Zhang, Y.M. Zhao, J.T. Liu, J. Xie, J. Wang, H. Li: Proc. XXV International Mineral Processing Congress (Brisbane, Australia, September 6-10, 2010), p.3095

[6] H. Wang, Y. He, C. Duan, Y. Zhao, Y. Tao, C. Ye: Advances in Computer Science and Engineering, Vol. 141, (2012), No.1, p.77.

[7] G.M. Qian, M.L. Li, T.J. Chen, W.B. Zhou: China Metallurgical Education, Vol. 22 (2013), No.3, p.5. (In Chinese)

[8] C. Michel and S.B. Ryan: User Modeling and User-Adapted Interaction, Vol. 22 (2012), No.1-2, p.9.

[9] S.F. Zhu, G.M. Qian, T.J. Chen: Chinese Educational Technology and Equipment, Vol. 27 (2013), No.3, p.142. (In Chinese)

[10]J. Uziak, M.T. Oladiran, E. Lorencowicz and M. Gizejowski: World Transactions on Engineering and Technology Education, Vol.14 (2016), No.2, p.251.

[11]W.B. Zhou, Y.M. Zhang, M.L. Li, T.J. Chen, G.M. Qian, D.B. Yang: China Metallurgical Education, Vol. 21 (2012), No.6, p.37. (In Chinese) 